\title{
Subsidy Policies in a Fertility Choice Model
}

\author{
MANUEL A. GÓMEZ*
}

This paper compares the effects that a subsidy to health expenditure or a subsidy to childrearing costs has in a fertility choice model in which mortality is also endogenously determined. Whichever subsidy is instituted, the population growth rate rises. While a subsidy to health expenditure reduces welfare, a subsidy to child-rearing costs might increase welfare. The welfare analysis also suggests that a subsidy to health expenditure should be financed by a capital income tax, while a subsidy to child-rearing costs should be financed by a consumption tax. (JEL J13, I12, H51) Atlantic Econ. J., 29(4): pp. 438-449, Dec. 01. CAll Rights Reserved

\section{Introduction}

The neoclassical model treats population growth as an exogenous factor. This hypothesis neglects interactions between the economic growth process and demographic trends. However, a genuine understanding of the economic growth process should take into account the extent to which fertility and mortality affect the population growth rate as an endogenous variable.

Following the work of Becker [1960], who analyses the behavior of demographic and economic changes in developed countries and the role of fertility, several authors have studied the feedback between population growth and development. Important works of reference are that of Becker and Barro [1988] and Barro and Becker [1989], where demographic and economic outcomes are jointly and endogenously determined.

The results obtained by the modern endogenous population literature have yielded insights into a wide range of issues, including the effects of tax and social security programs on fertility. This paper will focus on the effects that a subsidy to health expenditure or a subsidy to child-rearing costs has on welfare, population growth, and income. The effects of financing such a subsidy by a capital income tax and a consumption tax are also studied. The analysis is based on a continuous time version of the Becker and Barro [1988] model.

This paper is organized as follows. The second section presents the model, and the third section studies the effects of a government policy that subsidizes either the health expenditure or child-rearing costs that are financed either by a capital income tax or a consumption tax. Concluding remarks are given in the fourth section.

\section{The Model}

This paper considers an extension to the fertility choice model of Becker and Barro [1988] and Barro and Becker [1989], and the continuous time version set out in Barro and Sala-i-

\footnotetext{
${ }^{*}$ University of A Coruña-Spain.
} 
Martin [1995] and Blackburn and Cipriani [1998]. Time is continuous, all markets are perfectly competitive, and the economy has a large number of identical households that seek to maximize the intertemporal dynastic utility function [Barro and Sala-i-Martin, 1995], shown as:

$$
U=\int_{0}^{\infty} e^{-\rho t}\{\psi \ln N+\ln (c+\varphi g)+\varphi \ln (n-d(\hat{g}))\} d t
$$

where $\rho$ is the rate of time preference and represents parental altruism, $N$ is the size of the typical dynasty, $n$ is the family's fertility rate, $c$ is per capita consumption, $g$ is per capita health expenditure, $d(\hat{g})$ is the family's mortality rate, and $\hat{g}=g e^{-x t}$ is per capita health expenditure in terms of effective labor, with $x$ being the (exogenous) growth rate of technological progress. Households are assumed to give utility to their health status and, treating the health expenditure as a proxy to the health status, derive utility from the sequences of effective consumption, $z=c+\varphi g$. Parameter $\varphi$, where $0<\varphi<1$, indicates the extent to which each individual values his welfare in terms of health, as compared to consumption.

The mortality rate at time $t$ is assumed to be affected only by instantaneous health expenditure per efficiency unit of labor. Health has characteristics like capital that could be accumulated (for example, investing in health has a positive effect on mortality throughout the lifetime of a person). However, the modeling of this effect probably would be intractable in this context. Certain studies (for example, see Newhouse [1977]) argue that in countries with high expenditure, the marginal utility of medical care is more likely to produce improvements in so-called subjective components of health rather than improvements in morbidity and mortality rates. These works are based on the difference between caring and curing. Parkin et al. [1987] suggest that the "marginal utility of medical care" does produce an improvement in objective health status, but the cost of this marginal utility is greater for higher-income and higher-expenditure countries. Blackburn and Cipriani [1998] argue instead that greater spending in health is a means of mitigating the potential adverse effects on child welfare of greater economic activity. The hypothesis that the mortality rate depends on health expenditure per efficiency unit of labor seeks to capture these ideas: per capita health expenditure should grow more than economic activity, as proxied by the technological progress, to yield a lower mortality rate.

The mortality rate function, $d(\hat{g})$, is assumed to verify that $d(\hat{g})>0, d^{\prime}(\hat{g})<0$, and $d^{\prime \prime}(\hat{g})>0 \forall \hat{g} \geq 0$. In other words, the mortality rate decreases as $\hat{g}$ increases, but decreases in the mortality rate become less pronounced as health expenditure rises. Health gains are assumed to be effectively bounded, so that $\lim _{\hat{g} \rightarrow \infty} d(\hat{g})=\bar{d}$, with $0<\bar{d}<d(0)$. The size of the family changes continuously according to:

$$
d N / d t=(n-d(\hat{g})) N
$$

The model now introduces child-rearing costs $\Phi$, which would tend to increase as parental income increases or with other measures of the opportunity costs of parental time. Following 
Barro and Sala-i-Martin [1995], a linear function, $\Phi=b k$, is used. Thus, the family's budget constraint in per capita terms can be expressed as:

$$
d k / d t=w+\left(1-\tau_{k}\right) r k-(n-d(\hat{g})) k-\left(1-s_{b}\right) n b k-\left(1+\tau_{c}\right) c-\left(1-s_{g}\right) g-R,
$$

where $w$ is the wage rate, $r$ is the interest rate, $\tau_{c}$ is the consumption tax rate, $\tau_{k}$ is the rate of tax on capital income, $s_{g}$ is the rate of subsidy to health expenditure, $s_{b}$ is the rate of subsidy to child-rearing costs, and $R$ is a lump sum tax (or transfers). The government is assumed to run a balanced budget. Its budget constraint can be expressed as:

$$
\tau_{k} r k+\tau_{c} c+R=s_{b} n b k+s_{g} g
$$

A labor tax is not introduced since it acts much like a lump sum tax in this model.

The household optimization problem consists of maximizing (1) subject to (2) and (3). By solving the model (see Appendix), the following expressions are obtained:

$$
\begin{gathered}
d z / d t=\left(\left(1-\tau_{k}\right) r-\rho-\left(1+\left(1-s_{b}\right) b\right) n+d(\hat{g})\right) z, \\
n=d(\hat{g})+\frac{\varphi \rho \hat{z}\left(1+\tau_{c}\right)}{\rho\left(1+\left(1-s_{b}\right) b\right) \hat{k}-\psi\left(1+\tau_{c}\right) \hat{z}},
\end{gathered}
$$

and

$$
\hat{k}=\frac{\varphi\left(1+\tau_{c}\right)-\left(1-s_{g}\right)}{\left(1-s_{b}\right) b d^{\prime}(\hat{g})},
$$

where $\hat{k}=k e^{-x t}$ represents per capita capital in terms of effective labor. Equation (5) links the growth rate of per capita effective consumption with the rate of return on capital. Equation (6) indicates that, ceteris paribus, a higher fertility rate is associated with a higher mortality rate (and therefore a lower health expenditure), a higher $\varphi$ (which raises the marginal utility of the children), a higher $\psi$ (which raises the marginal utility of the family size), a lower rate of time preference, $\rho$, a lower $b$, a higher subsidy to child-rearing costs, $s_{b}$, and a higher consumption tax rate, $\tau_{c}$. In addition, a positive association exists between $n$ and $z / k$. Equation (7) shows that, ceteris paribus, a higher per capita capital in terms of effective labor is associated with a lower $\varphi$ (which decreases the weight of the health expenditure in the effective consumption, therefore decreasing the marginal utility of health expenditure), a lower $b$, a lower $\tau_{c}$, a higher subsidy to child-rearing costs, $s_{b}$, and a lower subsidy to health expenditure, $s_{g}$. In addition, a positive one-on-one relationship exists between per capita capital and per capita health expenditure in terms of effective labor. 
There are many firms in the market that act competitively and take technological progress as given. Output is produced with a Cobb-Douglas production function, $\hat{y}=A \hat{k}^{\alpha}$, where $0<\alpha<1$ and $\hat{y}=y e^{-x t}$ is per capita income in terms of effective labor. Profit maximization implies that firms pay the marginal product of factors:

$$
r=\alpha A \hat{k}^{\alpha-1}-\delta
$$

and

$$
w=(1-\alpha) A \hat{k}^{\alpha} e^{x t},
$$

where $\delta$ denotes the depreciation rate of physical capital.

By substituting (6), (8), and (9), and using (4), then (3) becomes:

$$
d \hat{k} / d t=A \hat{k}^{\alpha}-\left[\delta+x+\frac{\varphi \rho\left(1+\left(1-s_{b}\right) b\right)\left(1+\tau_{c}\right) \hat{z}}{\rho\left(1+\left(1-s_{b}\right) b\right) \hat{k}-\psi\left(1+\tau_{c}\right) \hat{z}}+b d(\hat{g})\right] \hat{k}-\hat{c}-\hat{g}
$$

Substituting (6) into (5), and given that $d \hat{z} / d t=d z / d t e^{-x t}-x \hat{z}$, the motion of effective consumption is given by:

$$
\begin{gathered}
\frac{d \hat{z} / d t}{\hat{z}}=\left(1-\tau_{k}\right)\left(\alpha A \hat{k}^{\alpha-1}-\delta\right)-\rho-\left(1-s_{b}\right) b d(\hat{g}) \\
-\frac{\varphi \rho\left(1+\left(1-s_{b}\right) b\right)\left(1+\tau_{c}\right) \hat{z}}{\rho\left(1+\left(1-s_{b}\right) b\right) \hat{k}-\psi\left(1+\tau_{c}\right) \hat{z}}-x,
\end{gathered}
$$

and differentiating (7) with respect to $t$ gives:

$$
d \hat{g} / d t=-\frac{\left(1-s_{b}\right) b d^{\prime}(\hat{g})^{2}}{\left(\varphi\left(1+\tau_{c}\right)-\left(1-s_{g}\right)\right) d^{\prime \prime}(\hat{g})} d \hat{k} / d t
$$

Substituting (10) into (12), using (7) to eliminate $\hat{k}$, and using $\hat{c}=\hat{z}-\varphi \hat{g}$ to eliminate $\hat{c}$, the former system, (11) and (12), can be expressed as a function of $\hat{g}$ and $\hat{z}$.

\section{Policy Analysis}

This section examines the effects that a subsidy has on welfare, income, and population growth. The situation in which there is no government intervention is compared with one in which there is alternatively a subsidy to health expenditure and a subsidy to child-rearing 
costs, which is financed either by a consumption tax or a capital income tax. The government is assumed to claim a fraction of output for its expenditure. Once the ratio of government expenditure to income, $\xi$, has been fixed, the corresponding subsidy and tax rates that maintain a balanced budget without using a lump sum tax in the steady state are determined. That is, if a subsidy to health expenditure is instituted, then $\xi y=s_{g} g=\tau_{c} c$ in the consumption tax setting and $\xi y=s_{g} g=\tau_{k} r k$ in the capital income tax setting at the new steady state. If a subsidy to child-rearing costs is introduced, then $\xi y=s_{b} n b k=\tau_{c} c$ and $\xi y=s_{b} n b k=\tau_{k} r k$, respectively.

First, some assumptions are made about $d(\hat{g})$ and the parameters of the model. The mortality rate is assumed to be related to health expenditure through a negative exponential function:

$$
d(\hat{g})=L+M \exp \left\{T \hat{g}^{s}\right\} .
$$

For $d$ to be a decreasing function, then $T<0$. This function verifies all the desirable features for the mortality rate implicit within the assumptions of the model. The natural mortality rate (in the absence of health expenditure) is $L+M$, and the threshold value of the mortality rate is $L$. The mortality rate cannot fall below this threshold value. Parameter $S$ reflects the rate at which the mortality rate decreases. Following Barro and Sala-i-Martin [1995] for the common parameters, the benchmark displayed in Table 1 is considered, with all tax and subsidy rates set equal to zero. With these parameter values, the fertility and mortality rates in the steady state are 1.5 percent and 0.8 percent, respectively, similar to the observed U.S. rates.

TABLE 1

Parameter Benchmark Values

\begin{tabular}{cccc}
\hline \hline Parameters & Values & Parameters & Values \\
\hline$L$ & 0.005 & $\rho$ & 0.020 \\
$M$ & 0.195 & $\psi$ & 0.200 \\
$T$ & -1.000 & $\varphi$ & 0.200 \\
$S$ & 0.500 & $\varphi$ & 0.200 \\
$\alpha$ & 0.750 & $\delta$ & 0.050 \\
$A$ & 1.000 & $x$ & 0.020 \\
$b$ & 1.000 & & \\
& & & \\
\hline
\end{tabular}

The welfare gain of a reform is measured as the constant permanent percentage increase in consumption, $\varepsilon$, keeping the population growth rate and health expenditure constant. This leaves the household indifferent between the lifetime utility obtained by remaining in the 
equilibrium without government intervention, and the lifetime utility obtained after the subsidy has been introduced. These simulations use the time elimination method [Mulligan and Sala-i-Martin, 1993].

Figures 1 and 2 show the evolution of per capita income in terms of effective labor and the fertility, mortality, and population growth rates after introducing a subsidy to health expenditure and a subsidy to child-rearing costs, financed either by a capital income tax or a consumption tax.

FIGURE 1

\section{Steady State After Instituting a Subsidy to Health Expenditure Financed by a Capital Income Tax or a Consumption Tax}

Per Capita Income in

Terms of Effective Labor

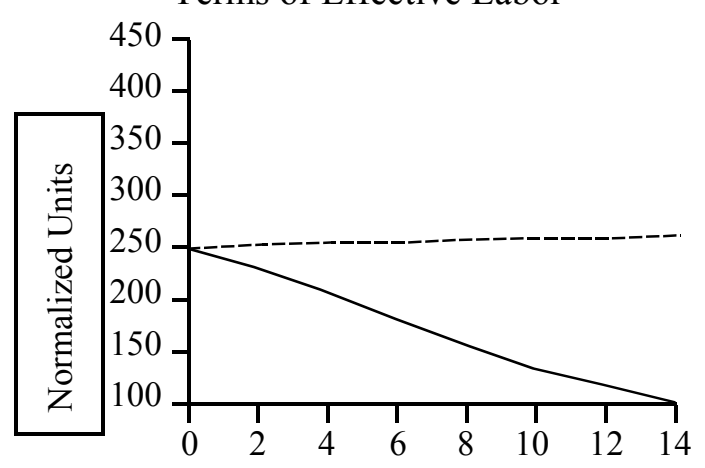

Fertility Rate

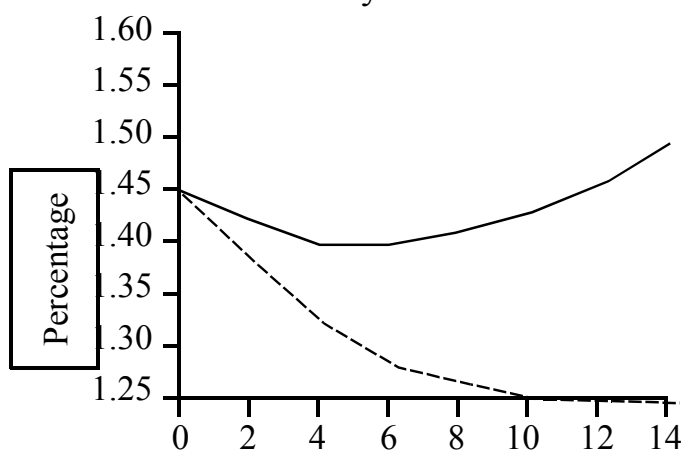

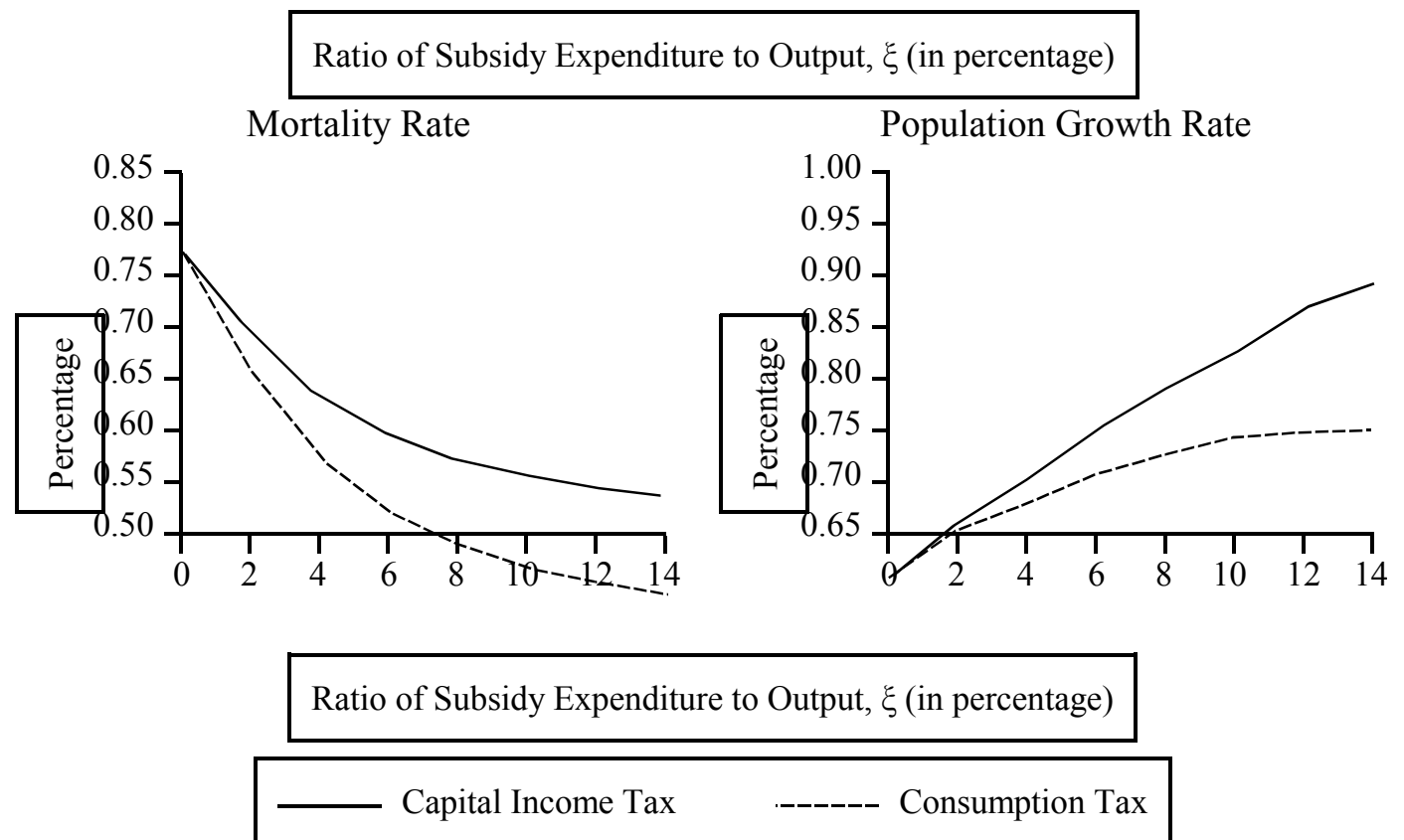


FIGURE 2

\section{Steady State After Instituting a Subsidy to Child-Rearing Costs Financed by a Capital Income Tax or a Consumption Tax}

Per Capita Income in

Terms of Effective Labor

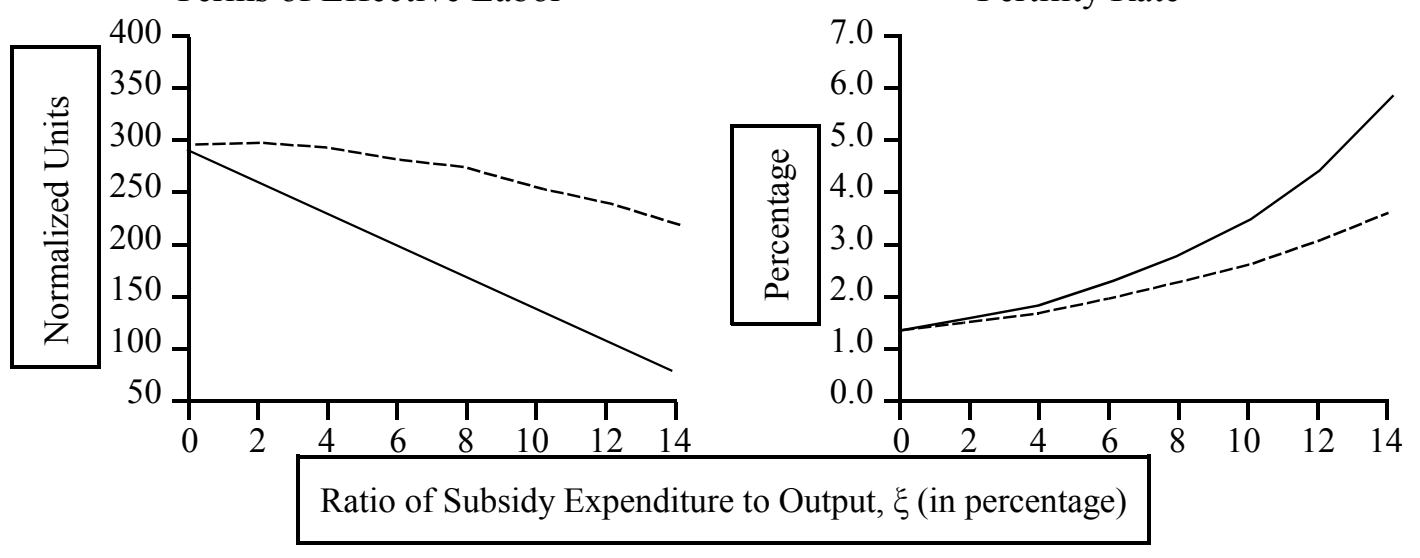

Mortality Rate

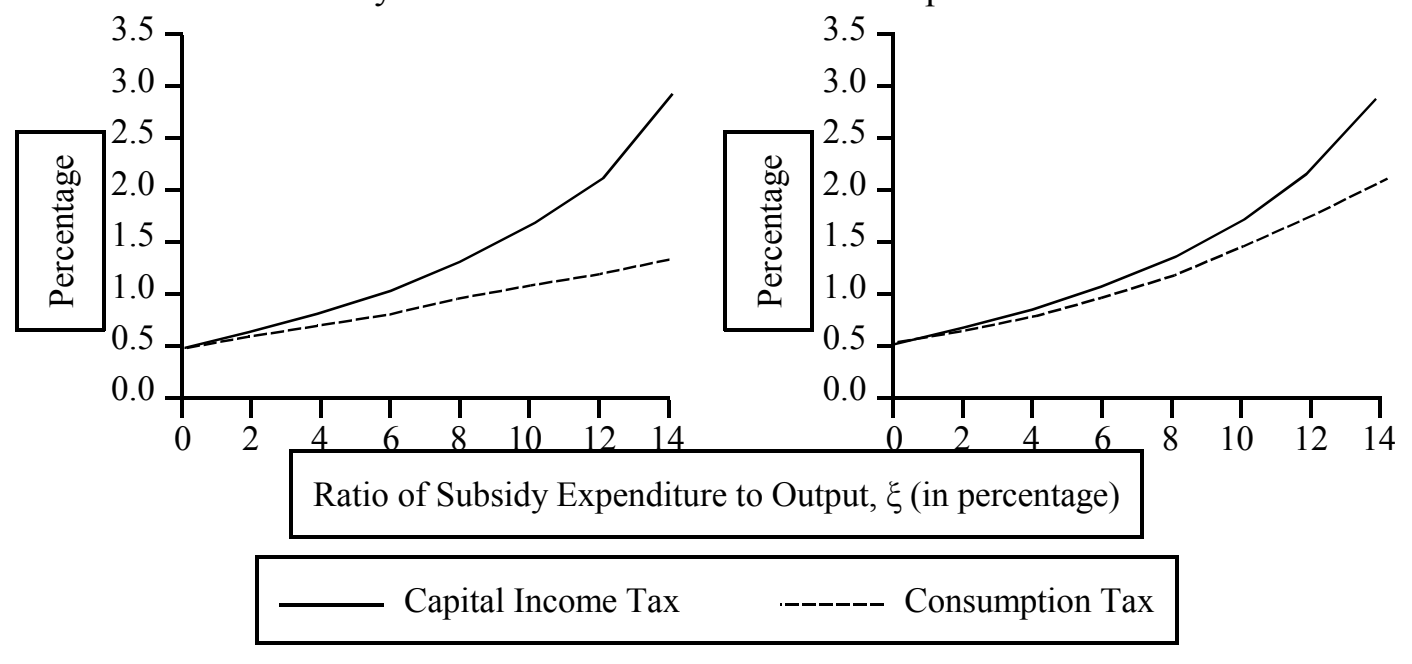

Introducing a subsidy to health expenditure decreases the mortality rate and increases the population growth rate with respect to the baseline situation, whether it is financed by a capital income tax or a consumption tax. However, per capita income slightly increases in the steady state in the consumption tax setting, while it falls in the capital income tax setting. The higher the subsidy, the more pronounced the effects are. When comparing both sources of financing, the fertility, mortality, and population growth rates are greater when the government finances the health subsidy by means of a capital income tax rather than by a consumption tax.

Introducing a subsidy to child-rearing costs decreases per capita income and increases the fertility, mortality, and population growth rates with respect to the baseline situation in the 
steady state, whether it is financed by a capital income tax or a consumption tax. Also, the higher the subsidy rate, the more pronounced these effects become. When comparing both sources of finance, the rise in the fertility, mortality, and population growth rates is lower if a consumption tax rather than a capital income tax is used. Per capita income in the new steady state diminishes with respect to the baseline situation whichever tax is used to finance the subsidy, but the reduction is greater if the subsidy is financed by means of a capital income tax.

Whichever subsidy is introduced, higher fertility, mortality, and population growth rates but lower per capita income are obtained if a consumption tax rather than a capital income tax is used to finance the subsidy. Furthermore, the rise in the fertility and population growth rates and the fall in per capita income are greater if a subsidy to child-rearing costs and not a subsidy to health expenditure is instituted.

Figure 3 shows the welfare gain or loss after instituting the subsidy. Introducing a subsidy to health expenditure yields a loss with respect to the baseline situation whether it is financed by a consumption or a capital income tax. Nevertheless, the loss of welfare is higher if consumption taxation is used to finance the health subsidy. This reflects the bigger effect of the subsidy on the population growth rate in the capital income taxation setting. As the extent of the subsidy increases, the welfare loss becomes greater.

\section{FIGURE 3}

\section{Welfare Gain (or Loss) After Instituting a Subsidy Financed by a Capital Income Tax or a Consumption Tax}

Subsidy to Health Expenditure

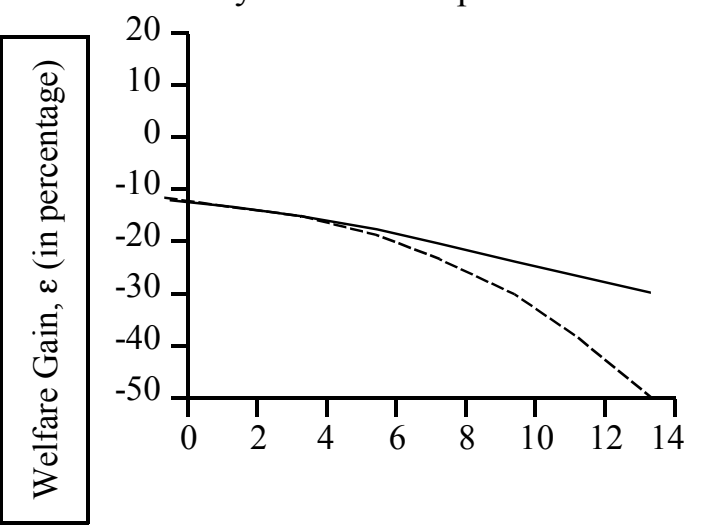

Subsidy to Child-Rearing Costs

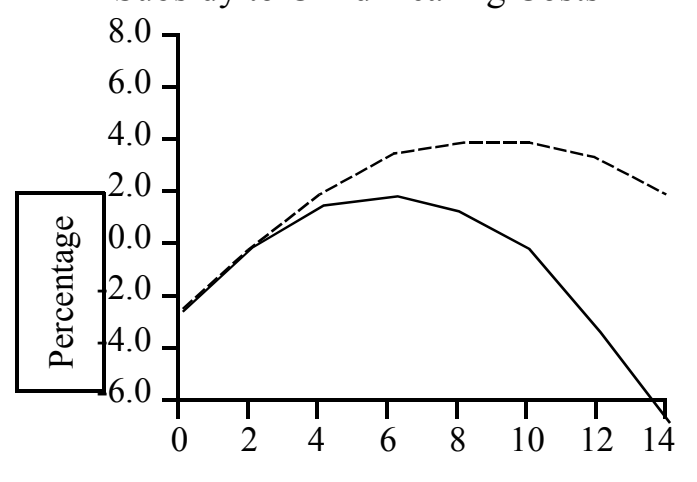

Ratio of Subsidy Expenditure to Output, $\xi$ (in percentage)

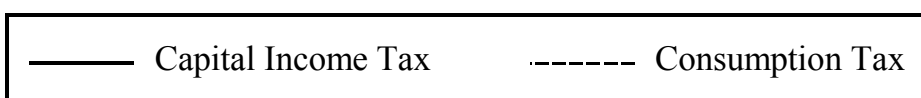

Subsidizing child-rearing costs might entail a welfare gain, depending on the extent of the subsidy and the way it is financed. The welfare gain first rises as the subsidy expenditure to output increases, then falls, turning even into a welfare loss in the capital income tax setting when the ratio of subsidy expenditure to output rises above approximately 12 percent. Furthermore, the gain in welfare is greater if a consumption tax is used to finance the 
subsidy. The maximum welfare gain attainable in the consumption tax setting is 6.5 percent and occurs when the ratio of subsidy expenditure to output is approximately 9 percent, the subsidy rate is about 54 percent, and the consumption tax rate is almost 31 percent. In the capital income tax setting, the maximum welfare gain is 4.4 percent, which is attained when the ratio of subsidy expenditure to output is about 6 percent, the subsidy rate is close to 41 percent, and the tax rate on capital income is approximately 13 percent.

The fact that introducing a subsidy to child-rearing costs might increase welfare is in accordance with the evidence seen on fiscal incentives to families with children [O'Donoghue and Sutherland, 1999] and other maternity benefits [Gruber, 1994]. The behavior of the welfare gain illustrated in Figure 3 suggests that a subsidy to health expenditure should be financed by a capital income tax, while a subsidy to child-rearing costs should be financed by a consumption tax instead.

Figure 4 shows the trends of per capita income, $\hat{y}$, and per capita consumption, $\hat{c}$, in terms of effective labor, using either a consumption tax or a capital income tax to finance a health subsidy. As the behavior of the variables remains consistent for distinct health subsidy values, the following case is considered where the ratio of subsidy expenditure to output, $\xi$, is 2 percent.

FIGURE 4

\section{Evolution of Per Capita Income and Per Capita Consumption in Terms of Effective Labor After Imposing a Subsidy to Health Expenditure}

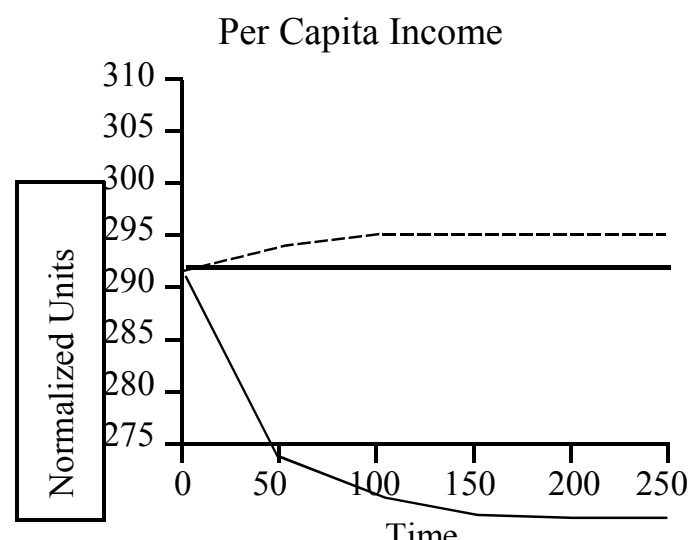

Time
Per Capita Consumption

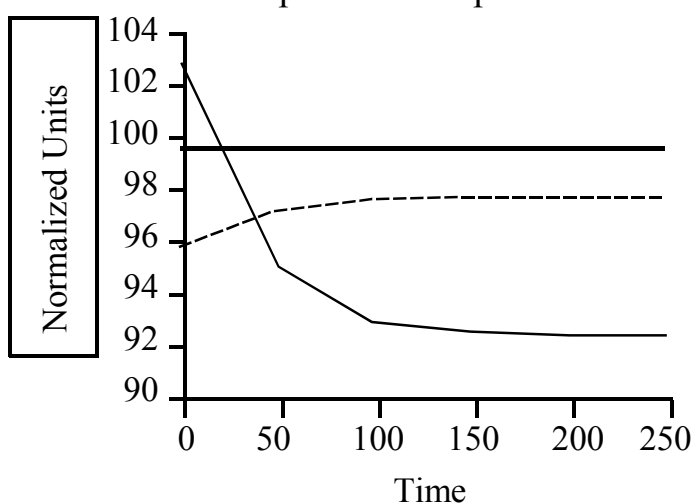

- Imposing a capital income tax

------ Imposing a consumption tax

Old steady state

Notes: The subsidy expenditure to output ratio is 2 percent.

Figure 4 shows that when a capital income tax is used, per capita income in terms of effective labor falls monotonically toward its new steady state value. Hence, along the transition path, the growth rate of per capita income, $y$, is below its steady state value of $x$. The opposite happens when a consumption tax is utilized. Per capita income in terms of effective labor increases monotonically toward its new steady state value, so its growth rate 
is positive and decreasing toward zero. Hence, the new steady state value of $\hat{y}$ is greater than the one obtained on the baseline.

It is worth noting how little the tax reform affects the growth rate of $\hat{y}$ along the transition path. In the capital income taxation setting, it ranges from -0.21 percentage points at the outset to -0.18 after 5 years and -0.14 after 15 years. In the case of a consumption tax, it ranges from 0.036 percentage points at the outset to 0.031 after 5 years and 0.024 after 15 years. This effect, though slight, can also be seen in the slow convergence toward the new steady state. In the consumption tax setting, 50 percent of the difference between the old and new steady state income is reduced in 26 years, and 75 percent of the difference is reduced in 52 years. Similar results are obtained in the capital income taxation setting.

Figure 5 shows the trends of per capita income and per capita consumption in terms of effective labor, using either a consumption tax or capital income tax to finance a subsidy to child-rearing costs when the ratio of subsidy expenditure to output, $\xi$, is 2 percent. When a capital income tax is used, per capita income in terms of effective labor falls monotonically toward its new steady state value. Hence, along the transition path, the growth rate of per capita income, $y$, is below its steady state value of $x$. While the same behavior happens when a consumption tax is used, the effect is less pronounced. Hence, the new steady state value of $\hat{y}$ is greater than the one obtained in the capital income taxation setting.

FIGURE 5

Evolution of Per Capita Income and Per Capita Consumption in Terms of Effective Labor After Imposing a Subsidy to Child-Rearing Costs

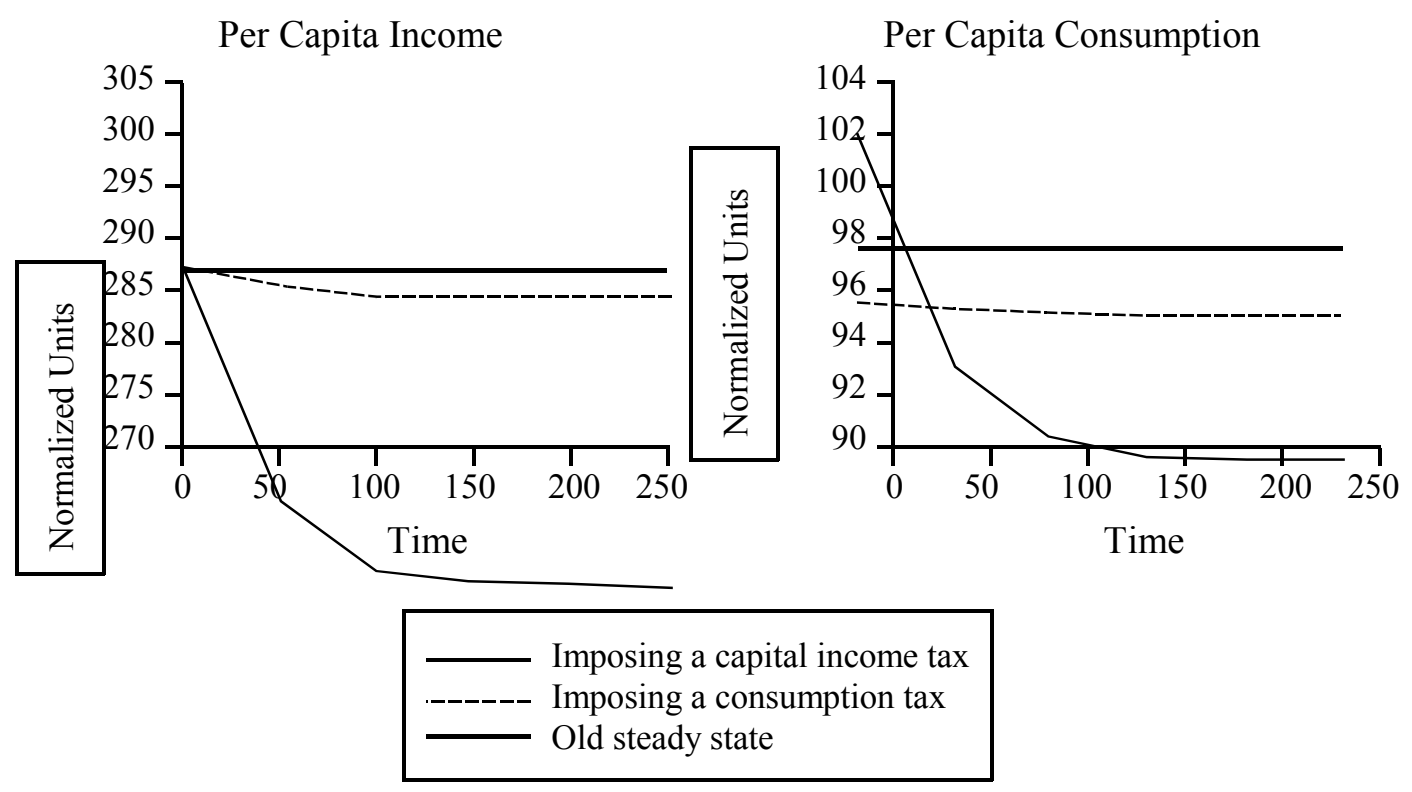

Notes: The subsidy expenditure to output ratio is 2 percent. 


\section{Conclusions}

This analysis of a government policy through the introduction of a health subsidy or a subsidy to child-rearing costs considers the use of a capital income tax and a consumption tax, alternatively, in order to finance the subsidy. The results suggest that a policy that subsidizes child-rearing costs increases the population growth rate and might have positive effects on welfare. The gain in welfare is greater and the increase in the population growth rate is lower if a consumption tax rather than a capital income tax is used to finance the subsidy. Instead, the introduction of a subsidy to health expenditure causes an unambiguous loss in welfare, and the rise in the population growth rate is less than the one obtained when a subsidy to child-rearing costs is instituted. The welfare analysis suggests that a subsidy to health expenditure should be financed by a capital income tax, while a subsidy to childrearing costs should be financed by a consumption tax.

\section{APPENDIX Solution to the Model}

Let $\mu$ and $v$ be multipliers for the constraints in (2) and (3) in the household optimization problem. The conditions for a maximum are:

$$
\begin{gathered}
e^{-\rho t} / z=\left(1+\tau_{c}\right) v, \\
e^{-\rho t} \varphi /(n-d(\hat{g}))-v\left(1+\left(1-s_{b}\right) b\right) k+\mu N=0, \\
+v\left(d^{\prime}(\hat{g}) e^{-x t} k-\left(1-s_{g}\right)\right)+\mu\left(-d^{\prime}(\hat{g}) e^{-x t}\right) N=0, \\
d v / d t=-v\left(\left(1-\tau_{k}\right) r-\left(1+\left(1-s_{b}\right) b\right) n+d(\hat{g})\right),
\end{gathered}
$$

and

$$
d \mu / d t=-e^{-\rho t}(\psi / N)-\mu(n-d(\hat{g}))
$$

Taking logarithms in (A1), differentiating with respect to time, and using (A4), results in (5). Substituting $v$ from (A1) into (A2) obtains: 


$$
\mu=-\frac{1}{N} e^{-\rho t}\left[\frac{\varphi}{n-d(\hat{g})}-\frac{\left(\left(1+\left(1-s_{b}\right) b\right) k\right.}{z\left(1+\tau_{c}\right)}\right]=-\frac{1}{N} e^{-\rho t} \Omega
$$

where $\Omega$ is the term in brackets. Differentiating (A6) with respect to time gives:

$$
d \mu / d t=-\left(e^{-\rho t / N}\right)(-((d N / d t) \Omega / N)-\rho \Omega+d \Omega / d t)
$$

Substituting (A6) into (A5) and substituting the result into the previous equation, gives $d \Omega / d t=\psi+\rho \Omega$, whose general solution is unstable:

$$
\Omega=-\psi / \rho+(\Omega(0)+\psi / \rho) e^{\rho t} .
$$

Substituting (A7) into (A6), the transversality condition $\lim _{t \rightarrow \infty} \mu N=0$ implies that $\Omega(0)=-\psi / \rho$. Hence, $\Omega=-\psi / \rho$, and by the definition of $\Omega,(6)$ is obtained. Substituting into (A3) the expressions for $v$ in (A1) and for $\mu$ in (A6) and simplifying, (7) is obtained.

\section{References}

Barro, Robert J.; Becker, Gary S. "Fertility Choice in a Model of Economic Growth," Econometrica, 57, 2, March 1989, pp. 481-501.

Barro, Robert J.; Sala-i-Martin, Xavier. Economic Growth, New York, NY: McGraw-Hill, 1995.

Becker, Gary S. "An Economic Analysis of Fertility," in Ansley J. Coale, ed., Demographic and Economic Change in Developed Countries, Princeton, NJ: Princeton University Press, 1960, pp. $209-40$.

Becker, Gary S.; Barro, Robert J. "A Reformulation of the Economic Theory of Fertility," Quarterly Journal of Economics, 103, 1, February 1988, pp. 1-25.

Blackburn, Keith; Cipriani, Giam P. "Endogenous Fertility, Mortality and Growth," Journal of Population Economics, 11, 4, 1998, pp. 517-34.

Gruber, Jonathan. "The Incidence of Mandated Maternity Benefits," American Economic Review, 84, 3, June 1994, pp. 622-41.

Mulligan, Casey B.; Sala-i-Martin, Xavier. "Transitional Dynamics in Two-Sector Models of Endogenous Growth," Quarterly Journal of Economics, 108, 3, August 1993, pp. 739-73.

Newhouse, Joseph. "Medical Care Expenditure: A Cross-National Survey," Journal of Human Resources, 12, 1, Winter 1977, pp. 115-25.

O'Donoghue, Cathal; Sutherland, Holly. "Accounting for the Family in European Income Tax Systems," Cambridge Journal of Economics, 23, 5, September 1999, pp. 565-98.

Parkin, David; McGuire, Alistair; Yule, Brian. "Aggregate Health Care Expenditures and National Income: Is Health Care a Luxury Good?," Journal of Health Economics, 6, 2, June 1987, pp. 10927. 